\title{
A 91-year-old woman with severe aortic stenosis successfully underwent maintenance hemodialysis via arteriovenous fistula after transcatheter aortic valve implantation: a case report with literature review
}

Minoru Yasukawa', Hiroki Omizo', Kazuhiro Sakai', Sachiko Kitagawa', Takahiro Kikuyama', Masaki Yamanaka', Fumika Ochiai ${ }^{1}$, Ryo Togashi ${ }^{1}$, Yoshikazu Nemoto ${ }^{1}$, Tatsuya Ota ${ }^{2}$, Hideyuki Kawashima ${ }^{2}$, Shintaro Takamura ${ }^{2}$, Yusuke Watanabe ${ }^{2}$, Ken Kozuma², Shigeru Shibata ${ }^{1}$ and Yoshihide Fujigaki ${ }^{*}$ (D)

\begin{abstract}
Background: Transcatheter aortic valve implantation (TAVI) has evolved to be a treatment of choice in high-risk patients with aortic stenosis (AS). However, it is not known whether TAVI is safe and beneficial for the creation of arteriovenous fistula for maintenance hemodialysis in high-risk patients with severe AS.

Case presentation: A 91-year-old woman was referred to our hospital due to oligoanuria and progressive renal dysfunction. She was diagnosed with anti-glomerular basement membrane (GBM) disease. She had hypertension, chronic kidney disease stage G3b, and AS. We chose not to perform immunosuppressive therapy and plasmapheresis for anti-GBM disease because the risk of death outweighed the benefit of treatment. Hemodialysis with a venous catheter was initiated for the renal indication. As she showed severe AS, she had a risk of cardiac decompensation after arteriovenous fistula creation for dialysis. Following the clinical decision-making process, she underwent TAVI. Although she required the implantation of a cardiac pacemaker for an advanced atrioventricular block that occurred 11 days after TAVI, arteriovenous fistula was successfully created thereafter. She could undergo maintenance hemodialysis using arteriovenous fistula.
\end{abstract}

Conclusions: TAVI is safe and beneficial for the creation of arteriovenous fistula shortly after initiating acute hemodialysis using a catheter in a very old patient with anti-GBM disease.

Keywords: Anti-glomerular basement membrane disease, Aortic stenosis, Arteriovenous fistula, Hemodialysis, Transcatheter aortic valve implantation

\footnotetext{
* Correspondence: fujigaki@med.teikyo-u.ac.jp

'Division of Nephrology, Department of Internal Medicine, Teikyo University

School of Medicine, 2-11-1 Kaga, Itabashi-ku, Tokyo, Japan

Full list of author information is available at the end of the article
}

(c) The Author(s). 2019 Open Access This article is distributed under the terms of the Creative Commons Attribution 4.0 International License (http://creativecommons.org/licenses/by/4.0/), which permits unrestricted use, distribution, and reproduction in any medium, provided you give appropriate credit to the original author(s) and the source, provide a link to the Creative Commons license, and indicate if changes were made. The Creative Commons Public Domain Dedication waiver (http://creativecommons.org/publicdomain/zero/1.0/) applies to the data made available in this article, unless otherwise stated. 


\section{Introduction}

Satisfactory hemodialysis (HD) requires arteriovenous fistula (AVF) for dialysis. AVF involves less complicated blood access for dialysis; however, AVF creation has a risk of high-output heart failure especially in patients with low cardiac function, including severe aortic stenosis (AS) $[1,2]$.

Transcatheter aortic valve implantation (TAVI) has revolutionized the treatment of high-risk patients with severe AS. The relative survival after TAVI is high, and survival rates in those aged $>85$ years are approximately those of a matched general population within 3 years [3]. TAVI is feasible in patients with not only chronic kidney disease (CKD) stage G3-5 [4] but also CKD stage G5D [5]. However, it is not known whether TAVI is safe and beneficial for the creation of AVF in old patients with severe AS shortly after initiating acute HD using a venous catheter.

We describe a 91-year-old woman who presented with oligoanuria and deteriorated renal function requiring acute HD due to anti-glomerular basement membrane (GBM) disease. Although she had severe AS, she could successfully undergo maintenance HD with AVF creation after TAVI.

\section{Case presentation}

A 91-year-old woman presented with general fatigue, appetite loss, and oligoanuria 10 days before her regular visit at our hospital. She had hypertension, CKD stage G3b (serum creatinine level of approximately $1.5 \mathrm{mg}$ / $\mathrm{dL}$ ), and AS. She had been taking amlodipine at a dosage of $5 \mathrm{mg} /$ day for hypertension and furosemide at a dosage of $10 \mathrm{mg} /$ day for chronic heart failure due to AS. Laboratory data showed a blood urea nitrogen level of 115 $\mathrm{mg} / \mathrm{dL}$, a serum creatinine level of $14.3 \mathrm{mg} /$ day and a Creactive protein level of $7.11 \mathrm{mg} / \mathrm{dL}$. She was admitted to our hospital due to deteriorating renal function with anuria.

The physical examination upon admission showed a height of $144.0 \mathrm{~cm}$, a body weight of $52.0 \mathrm{~kg}$, a body temperature of $36.0^{\circ} \mathrm{C}$, a blood pressure of $164 / 90$ $\mathrm{mmHg}$, an irregular heart rate of 89 beats/min, and an $\mathrm{SpO}_{2}$ of $98 \%$. Mid-systolic ejection murmur was audible over the right second intercostal space. Normal vesicular breath sounds were heard in the chest. Pitting edema was found in both lower legs. Urine samples were not collected because of anuria. The results of blood tests upon admission are listed in Table 1. The patient showed anemia, hypoproteinemia, and severe renal impairment in association with a high level of C-reactive protein and a high titer of anti-GBM antibody. She also showed a high level of NT-proBNP. Chest X-ray did not show pulmonary hemorrhage but did show pleural effusion and cardiomegaly (Fig. 1a). Computed tomography
Table 1 Laboratory data upon admission

\begin{tabular}{|c|c|}
\hline \multicolumn{2}{|l|}{ Complete blood count } \\
\hline WBC & $8900 / \mu \mathrm{L}$ \\
\hline $\mathrm{Hb}$ & $9.3 \mathrm{~g} / \mathrm{dL}$ \\
\hline Platelet & $30.9 \times 10^{4} / \mu \mathrm{L}$ \\
\hline \multicolumn{2}{|l|}{ Blood chemistry } \\
\hline Total protein & $6.2 \mathrm{~g} / \mathrm{dL}$ \\
\hline Albumin & $2.3 \mathrm{~g} / \mathrm{dL}$ \\
\hline Urea nitrogen & $115.4 \mathrm{mg} / \mathrm{dL}$ \\
\hline Creatinine & $14.13 \mathrm{mg} / \mathrm{dL}$ \\
\hline Aspartate aminotransferase & $9 \| \mathrm{U} / \mathrm{L}$ \\
\hline Alanine aminotransferase & $4 \mathrm{IU} / \mathrm{L}$ \\
\hline Total bilirubin & $0.2 \mathrm{mg} / \mathrm{dL}$ \\
\hline Alkaline phosphatase & $375 \mathrm{IU} / \mathrm{L}$ \\
\hline Y-glutamyltransferase & $23 \mathrm{IU} / \mathrm{L}$ \\
\hline Lactate dehydrogenase & $160 \mathrm{IU} / \mathrm{L}$ \\
\hline $\mathrm{Na}$ & $137 \mathrm{mEq} / \mathrm{L}$ \\
\hline K & $4.3 \mathrm{mEq} / \mathrm{L}$ \\
\hline $\mathrm{Cl}$ & $104 \mathrm{mEq} / \mathrm{L}$ \\
\hline NT-proBNP & $40,998 \mathrm{pg} / \mathrm{mL}$ \\
\hline Estimated GFR & $2.2 \mathrm{~mL} / \mathrm{min} / 1.73 \mathrm{~m}^{2}$ \\
\hline \multicolumn{2}{|l|}{ Immunologic test } \\
\hline $\lg G$ & $1760 \mathrm{mg} / \mathrm{dL}$ \\
\hline $\lg A$ & $235 \mathrm{mg} / \mathrm{dL}$ \\
\hline $\lg M$ & $71 \mathrm{mg} / \mathrm{dL}$ \\
\hline $\mathrm{CH} 50$ & $60 \mathrm{U} / \mathrm{mL}$ \\
\hline C3 & $82 \mathrm{mg} / \mathrm{dL}$ \\
\hline C4 & $33 \mathrm{mg} / \mathrm{dL}$ \\
\hline C-reactive protein & $7.11 \mathrm{mg} / \mathrm{dL}$ \\
\hline Antinuclear antibody & $\times 80$ \\
\hline Anti-DNA antibody & $1.8 \mathrm{IU} / \mathrm{mL}(<9.0)$ \\
\hline MPO-ANCA & $1.0 \mathrm{U} / \mathrm{mL}(<3.4)$ \\
\hline PR3-ANCA & $1.0 \mathrm{U} / \mathrm{mL}(<3.4)$ \\
\hline Anti-GBM antibody & $350.0 \mathrm{U} / \mathrm{mL} \leqq(<3)$ \\
\hline Cryoglobulin & Positive \\
\hline HBs antigen & Negative \\
\hline HCV antibody & Negative \\
\hline
\end{tabular}

GFR glomerular filtration rate, MPO-ANCA myeloperoxidase-anti-neutrophil cytoplasmic antibody, PR3-ANCA proteinase 3-anti-neutrophil cytoplasmic antibody, GBM glomerular basement membrane, $H B$ s hepatitis B surface antigen, $H C V$ hepatitis $C$ virus. The values in the parentheses show the normal range

showed cardiomegaly, bilateral pleural effusion, interstitial changes at the base of the lungs, esophageal herniation, and slightly atrophic kidneys (Fig. 1b). She was diagnosed with rapidly progressive glomerulonephritis due to anti-GBM disease.

Following the clinical decision-making process with her and her family members, we chose not to perform immunosuppressive therapy and plasmapheresis for her anti-GBM disease because the risk of death caused by 

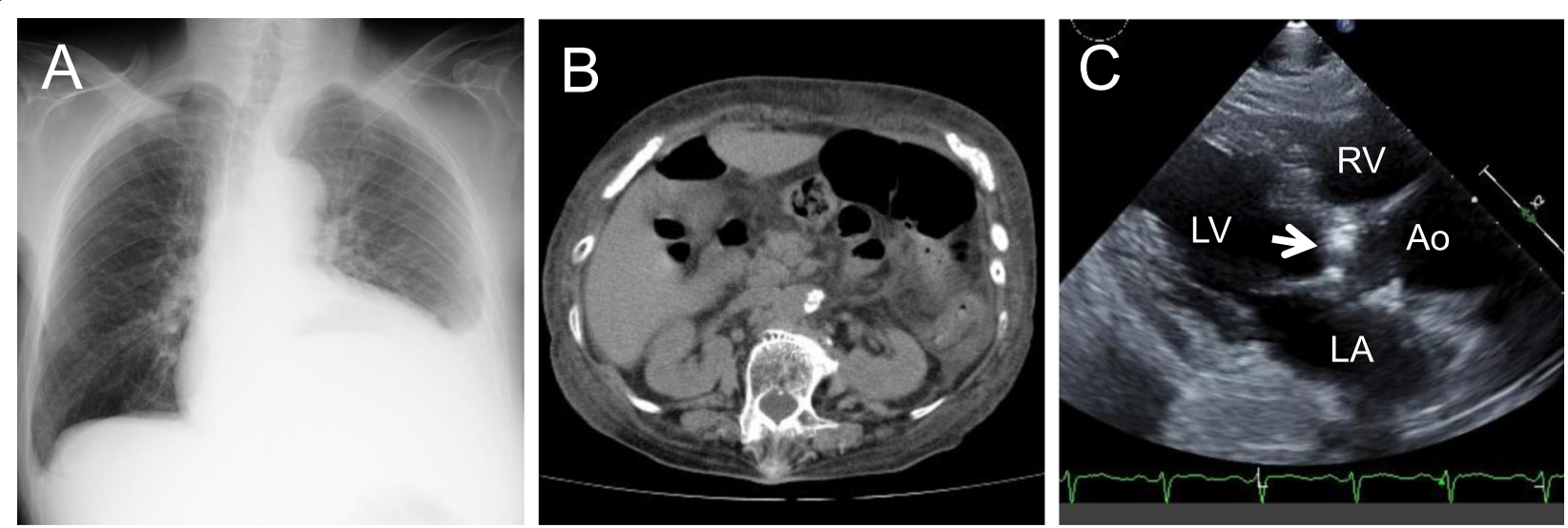

Fig. 1 Image findings after admission. a Chest X-ray (posteroanterior erect view) showing pleural effusion and cardiomegaly. b Computed tomography showing slightly atrophic kidneys. c Echocardiogram (parasternal long-axis view) showing severe calcific aortic stenosis (arrow). RV, right ventricle; LV, left ventricle; LA, left atrium; Ao, aorta

severe infection outweighed the benefits of treatment. She initiated intermittent HD due to anuria at the right internal jugular vein using a venous catheter on the 3rd day after admission. She could undergo HD well with a dialyzer (membrane surface area of $1.0 \mathrm{~m}^{2}$, ultrafiltration rate of $37 \mathrm{~mL} / \mathrm{h} / \mathrm{mmHg}$, and blood flow rate of 100 to $150 \mathrm{~mL}$ during HD).

Doppler echocardiography after an HD session demonstrated a low flow (peak jet velocity of $3.5 \mathrm{~m} / \mathrm{s}$, systolic volume index $34 \mathrm{~mL} / \mathrm{m}^{2} / 1.73 \mathrm{~m}^{2}$ body surface area), a low gradient (mean pressure gradient $24 \mathrm{mmHg}$ ), aortic valve stenosis (aortic valve area $0.56 \mathrm{~cm}^{2}$ ), and reduced left ventricular ejection fraction (LVEF 46\%) (Fig. 1c). Therefore, she was diagnosed with classic low flow, low gradient severe AS.

We considered that she had a substantial risk for cardiac decompensation after AVF creation for dialysis. Since her family claimed that it was difficult to support her appropriately, peritoneal dialysis could not be performed in the patient. In such cases, HD access, such as a permanent central catheter or arterial superficialization, might be preferable. However, although the patient was very old, she did not have dementia or malignancy and could walk in her house. Therefore, after another decision-making process, we chose to perform TAVI as a treatment for heart failure to create AVF. Coronary angiography before TAVI revealed $75 \%$ stenosis in the mid-left anterior descending coronary artery. She underwent TAVI under general anesthesia on the 42nd day after admission. A transcatheter heart valve (The Edwards Sapien $323 \mathrm{~mm}$ ) was implanted via the transfemoral approach without any major complications. Doppler echocardiography after an HD session showed a slightly increased LVEF of $49 \%$. The echocardiographic data upon admission and after TAVI are shown in Table 2. Eleven days after TAVI, she complained of breathlessness and showed hypotension due to bradycardia with an advanced atrioventricular (AV) block (3:1 or 4:1 conduction ratio) (Fig. 2). A MicraTranscathether Pacing System ${ }^{\circ}$ (Medtronic, Minneapolis, MN, USA) for AV block was implanted in the right ventricle by using a femoral percutaneous approach. AVF for dialysis was successfully constructed in the left elbow 22 days after TAVI because of superficial venous stenosis in the forearm. Twenty-two days after AVF creation, she began to undergo HD with a blood flow rate of $150 \mathrm{~mL} / \mathrm{min}$ for 3 $\mathrm{h}$ via AVF. The NT-proBNP levels 11 days before and 7 days after TAVI were $63,579 \mathrm{pg} / \mathrm{mL}$ and $110,427 \mathrm{pg} / \mathrm{mL}$, respectively. The NT-proBNP level did not decrease in the short term after TAVI. Although the titers of antiGBM antibody were maintained at approximately $300 \mathrm{U} /$ $\mathrm{mL}$ during the length of stay, the level of C-reactive protein was decreased to $0.24 \mathrm{mg} / \mathrm{dL}$ just before TAVI, and pulmonary hemorrhage did not occur throughout her clinical course. Eleven months after TAVI, she underwent maintenance HD well in another hospital.

\section{Discussion}

Our patient showed deteriorating renal function and the presence of serum anti-GBM antibody. Therefore, she was diagnosed with anti-GBM disease on CKD. To our knowledge, our patient, a 91-year-old woman, was the oldest patient at the onset of anti-GBM disease described in the English literature. Prior to our patient, the oldest reported patient in the English literature was a 90-year-old woman [6]. The current recommendation for the treatment of anti-GBM disease is the early introduction of immunosuppressants and plasmapheresis [7]. However, recovery of renal function rarely occurs in patients with advanced stages of anti-GBM disease at presentation, where predictors of dialysis dependence, such as oliguria, requiring $\mathrm{HD}$ and a high percentage of 
Table 2 Echocardiographic data before and after TAVI

\begin{tabular}{lll}
\hline & $\begin{array}{l}\text { 27 days before } \\
\text { TAVI }\end{array}$ & $\begin{array}{l}\text { 19 days after } \\
\text { TAVI }\end{array}$ \\
\hline EF (\%) & 46 & 49 \\
Aortic jet velocity $(\mathrm{m} /$ second) & 3.5 & 2.58 \\
Mean pressure gradient $(\mathrm{mmHg})$ & 24 & 18 \\
Aortic valve area $(\mathrm{AVA})\left(\mathrm{cm}^{2}\right)$ & 0.56 & 1.06 \\
Indexed AVA $\left(\mathrm{cm}^{2} / \mathrm{m}^{2}\right)$ & 0.39 & 0.75 \\
\hline
\end{tabular}

crescent formation have been observed [8-10]. In this poor outcome group, especially in those without pulmonary hemorrhage, the risks of treatment may far outweigh the benefits [11]. Based on these findings, our patient began to undergo HD using a venous catheter for renal indication without immunosuppressant therapy and plasmapheresis.

AVF and arteriovenous grafts are considered the optimal choices for HD access in patients who initiate and maintain permanent HD. However, excessive cardiac burden due to AVF must be considered in patients with severely impaired cardiac function [12].

A survey of international surgeons reported that based on the surgeons' preferences, the absolute contraindications to AVF creation included a patient life expectancy $<1$ year, an LVEF $<15 \%$, and a history of dementia, while $42 \%$ of surgeons reported no absolute contraindications [13]. Patients with a significant reduction in systolic function (LVEF <30\%) are reported to be candidates for tunneled catheter placement to start HD treatment [14]. It has been reported that the potential effect of AVF creation is the increase in cardiac output (CO) due to a left-to-right extracardiac shunt, resulting in acute or subacute decompensation in patients with substantial AS who have minimal symptoms before AVF creation [2]. We considered that our patient had a high risk for AVF creation; thus, we decided to postpone AVF creation until the patient underwent TAVI.

Recently, TAVI has evolved as the treatment of choice in high-risk patients with severe AS. Although TAVI is a less invasive treatment than aortic valve replacement, TAVI itself has several risks, such as hemorrhage with vascular damage, embolic stroke, severe conduction abnormalities with left bundle branch block, or complete AV block, paravalvular leakage, and infective endocarditis [15]. However, the relative survival after TAVI is high, and survival rates in those aged $>85$ years are approximately those of a matched general population within 3 years [3]. TAVI does not seem to bear an increased risk for patients with CKD stage G3-5 [4]. Satisfactory early results have been achieved with TAVI in Japanese dialysis patients with a high surgical risk [16]. TAVI is feasible not only in patients with CKD stage G5D but also in kidney transplant recipients [5]. However, depending on the prosthesis, 8.5 to $25.9 \%$ of patients undergoing TAVI require a permanent pacemaker within 30 days after the procedure [17]. Our patient had AV block as a possible complication of TAVI, which could be managed by a leadless cardiac pacemaker. AVF for dialysis could be safely created, and the patient could undergo maintenance HD via AVF.

\section{Mini review}

\section{The impact of AVF on AS}

AVF is associated with low infection and mortality rates as well as a low cost and hence has become the vascular access of choice for patients needing HD [18]. However, AVF creation has significant effects on cardiac functions

A

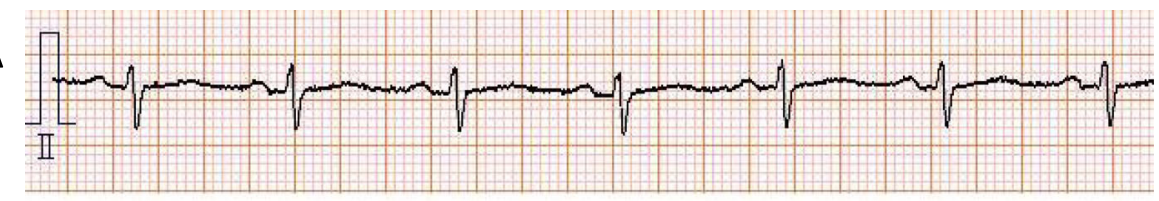

B
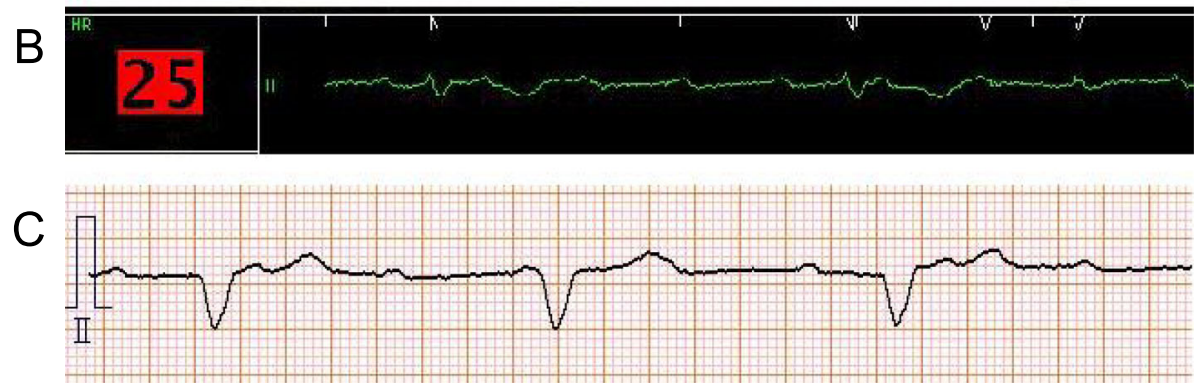

Fig. 2 Sequential electrocardiogram changes before and after TAVI. a Normal sinus rhythm 12 days before TAVI. b Bradycardia with an advanced atrioventricular block on the ECG monitor 11 days after TAVI. c After implant A MicraTranscathether Pacing System. Settings WI 40 ppm back up pacing 
Table 3 A summary of studies examining the outcomes of transcatheter aortic valve implantation (TAVI) or transcatheter aortic valve replacement (TAVR) in dialysis patients

\begin{tabular}{|c|c|c|c|c|c|c|}
\hline Study/country & Design & $N^{*}$ & Mean age \pm SD & Short-term outcome (\%) & Long-term outcome (\%) & Reference \\
\hline Szerlip M et al. 2019/USA & Prospective & 3053 & 76 & $\begin{array}{l}\text { In-hospital mortality (5.1) } \\
\text { 1-year mortality (36.8) }\end{array}$ & & [25] \\
\hline Schymik et al. 2019/Germany & Prospective & 56 & $76.6 \pm 6.4$ & $\begin{array}{l}\text { Perioperative mortality (10.7) } \\
\text { 1-year survival }(57.1)\end{array}$ & 3-year survival (26.8) & [23] \\
\hline Al-Rashid et al. 2017/Germany & Retrospective & 22 & $79 \pm 5$ & 30-day mortality (4.5) & 2-year mortality (53) & {$[5]$} \\
\hline Bhatia et al. 2017/USA & Retrospective & 1708 & $75.3 \pm 9.9$ & In-hospital mortality (8.2) & & [26] \\
\hline Szerlip et al. 2016/USA & Retrospective & 43 & $76.2 \pm 11$ & $\begin{array}{l}\text { Operative mortality (14) 6-month } \\
\text { mortality (25.6) }\end{array}$ & & {$[27]$} \\
\hline Maeda et al. 2015/Japan & Prospective & 17 & $76.7 \pm 5$ & 1-year overall mortality (0) & & {$[16]$} \\
\hline $\begin{array}{l}\text { Dumonteil et al. 2013/France, } \\
\text { the Netherlands, Italy }\end{array}$ & Retrospective & 33 & $76.1 \pm 7.3$ & $\begin{array}{l}\text { 30-day all-cause mortality (15.2) } \\
1 \text {-year survival (54.8) }\end{array}$ & & [28] \\
\hline Rau et al. 2012/Germany & Retrospective & 10 & $72.3 \pm 64$ & 30-day overall mortality (0) & & [29] \\
\hline
\end{tabular}

*Number of dialysis patients. Only dialysis patients were depicted from each study

predominantly related to the increase in preload and $\mathrm{CO}$ in the setting of preexisting heart disease, such as AS [2]. There seems to be two major effects of AVF on patients with severe AS: (1) worsening heart failure after AVF creation should be considered. There has only been one case report in the English literature, where the increase in $\mathrm{CO}$ associated with AVF creation resulted in acute severe heart failure in the patient with normal ventricular function but severe AS who had no symptoms prior to AVF creation [19]. Accordingly, patients with severe AS may have alternative choices of tunneled central catheter placement/arterial superficialization for vascular access or performing peritoneal dialysis. The efficacy of TAVI on AVF creation to avoid cardiac decompensation, as in our case, has not been reported in patients with severe AS. (2) The coexistence of severe AS and AVF may largely affect the assessment of the severity of AS in dialysis patients. It has been reported that manual compression of AVF can induce significant alterations in transvalvular flow rates and valvulo-arterial impedance that influence the grading of stenosis severity [20].

\section{The impact of TAVI in dialysis patients}

To our knowledge, there is no English literature about the impact of TAVI carried out immediately after HD introduction using venous catheters in patients with acute kidney injury or rapidly progressive glomerulonephritis, as in our case. However, the hemodynamics in our patient might have been similar to those in maintenance dialysis patients with severe AS. The higher prevalence and quicker progression of AS are known in maintenance dialysis patients compared with the general population [21, 22], and end-stage kidney disease with dialysis affects approximately 2 to $4 \%$ of patients with severe AS [23]. After the appearance of symptoms, severe AS is associated with a high rate of death if patients are left untreated [24]. At present, aortic valve replacement is the only definitive treatment for chronic HD patients with severe AS in Japan. However, there are an increasing number of studies about the impact of TAVI in chronic dialysis patients with severe AS who are unable to undergo safe open surgical therapy. A summary of studies on the outcomes of TAVI or transcatheter aortic valve replacement (TAVR) in chronic HD patients is provided in Table 3. Unfortunately, there is no information as to whether patients underwent HD via an AVF/ arteriovenous graft, a tunneled central catheter or arterial superficialization in the studies. The mortality rates in the short-term (30 days/1 year) and long-term (2 years/ 3 years) periods after TAVI are 0 to $15.2 \% / 0$ to $45.2 \%$ and $53 \% / 73.2 \%$, respectively [ $5,15,23,25-29]$. At present, the Japanese healthcare system does not reimburse TAVI for dialysis patients. A clinical trial of TAVI in dialysis patients (JAPAN) (ClinicalTrials.gov Identifier: NCT02903420) that evaluates the safety and effectiveness of the Edwards SAPIEN 3 Transcatheter Hear Valve System for the treatment of symptomatic severe AS patients on chronic dialysis is currently ongoing. One of the inclusion criteria of the clinical trial is that "patient has been on dialysis (hemodialysis or peritoneal dialysis) in stable condition for $\geq 3$ months." Our patient was an acute, unstable dialysis patient who entered the exclusion criteria of the trial.

\section{Conclusions}

TAVI is safe and beneficial for the creation of AVF shortly after initiating acute HD using a dialysis catheter before undergoing maintenance HD in a very old patient with rapidly progressive glomerulonephritis due to antiGBM disease.

\section{Abbreviations}

AS: Aortic stenosis; AV: Arteriovenous fistula; AV: Atrioventricular; CK: Chronic kidney disease; CO: Cardiac output; GBM: Glomerular basement membrane; 
HD: Hemodialysis; LVEF: Left ventricular ejection fraction; TAVI: Transcatheter aortic valve implantation; TAVR: Transcatheter aortic valve replacement

\section{Acknowledgements \\ Not applicable}

\section{Authors' contribution}

MY, HO, KS, SK, TK, MY, FO, RT, YN, TO, HK, ST, YW, KK, and SS analyzed and interpreted the patient data. TO, HK, ST, YW, and KK performed TAVI as a heart team. YF drafted the manuscript and is responsible for the final version of the manuscript. All authors read and approved the final manuscript.

\section{Funding}

The authors declare that there is no funding related to this manuscript.

\section{Availability of data and materials}

Data sharing was not applicable to this article because no datasets were generated during the current study.

\section{Ethics approval and consent to participate}

The case report was written in compliance with the Declaration of Helsinki.

\section{Consent for publication}

Written informed consent was obtained from the patient for the publication of this case report.

\section{Competing interests}

The authors declare that they have no competing interests.

\section{Author details}

'Division of Nephrology, Department of Internal Medicine, Teikyo University School of Medicine, 2-11-1 Kaga, Itabashi-ku, Tokyo, Japan. ${ }^{2}$ Division of Cardiology, Department of Internal Medicine, Teikyo University School of Medicine, 2-11-1 Kaga, Itabashi-ku, Tokyo, Japan.

Received: 12 August 2019 Accepted: 20 November 2019

Published online: 16 December 2019

\section{References}

1. Basile C, Lomonte C, Vernaglione L, Casucci F, Antonelli M, Losurdo N. The relationship between the flow of arteriovenous fistula and cardiac output in haemodialysis patients. Nephrol Dial Transplant. 2008;23:282-7.

2. Alkhouli M, Sandhu P, Boobes K, Hatahet K, Raza F, Boobes Y. Cardiac complications of arteriovenous fistulas in patients with end-stage renal disease. Nefrologia. 2015:35:234-45.

3. Martin GP, Sperrin M, Hulme W, Ludman PF, de Belder MA, Toff WD, et al. National Institute of Cardiovascular Outcomes Research (NICOR). Relative survival after transcatheter Aortic valve implantation: how do patients undergoing transcatheter aortic valve implantation fare relative to the general population? J Am Heart Assoc. 2017;6:e007229.

4. Wessely M, Rau S, Lange P, Kehl K, Renz V, Schönermarck U, et al. Chronic kidney disease is not associated with a higher risk for mortality or acute kidney injury in transcatheter aortic valve implantation. Nephrol Dial Transplant. 2012:27:3502-8.

5. Al-Rashid F, Bienholz A, Hildebrandt HA, Patsalis PC, Totzeck M, Kribben A, et al. Transfemoral transcatheter aortic valve implantation in patients with end-stage renal disease and kidney transplant recipients. Sci Rep. 2017;7: 14397.

6. Okiro JO, Ebad CA, Khan AZ. Atypical presentation of anti-GBM nephritis in a 90-year-old patient. BMJ Case Rep. 2016. https://doi.org/10.1136/bcr-2016217990.

7. Kidney Disease: Improving Global Outcomes (KDIGO) Glomerulonephritis Work Group. KDIGO Clinical Practice Guideline for Glomerulonephritis. Kidney Int. 2012;(Suppl 2):139-274.

8. Hind CRK, Lockwood CM, Peters DK, Paraskevakou H, Evans DJ, et al. Prognosis after immunosuppression of patients with crescentic nephritis requiring dialysis. Lancet. 1983:321:263-5.

9. Levy JB, Turner AN, Rees AJ, Pusey CD. Long-term outcome of antiglomerular basement membrane antibody disease treated with plasma exchange and immunosuppression. Ann Intern Med. 2001;134:1033-42.
10. Alchi B, Griffiths $M$, Sivalingam $M$, Jayne $D$, Farrington K. Predictors of renal and patient outcomes in anti-GBM disease: clinicopathologic analysis of a two-centre cohort. Nephrol Dial Transplant. 2015;30:814-21.

11. Kluth DC, Rees AJ. Anti-glomerular basement membrane disease. J Am Soc Nephrol. 1999;10:2446-53.

12. Mise N, Uchida L, Tanaka M, Tanaka S, Nakajima H, Sugimoto T. Acute systemic hypotension after arteriovenous fistula construction in a patient with severe aortic stenosis. Clin Exp Nephrol. 2011;15:788-90.

13. Nica A, Lok CE, Harris J, Lee TC, Mokrzycki MH, Maya ID, et al. North American Vascular Access Consortium (NAVAC). Understanding surgical preference and practice in hemodialysis vascular access creation. Semin Dial. 2013;26:520-6.

14. Roca-Tey R. Permanent arteriovenous fistula or catheter dialysis for heart failure patients. J Vasc Access. 2016;17(Suppl 1):S23-9.

15. Cahill TJ, Chen M, Hayashida K, Latib A, Modine T, Piazza N, et al. Transcatheter aortic valve implantation: current status and future perspectives. Eur Heart J. 2018;39:2625-34.

16. Maeda K, Kuratani T, Torikai K, Ichibori Y, Nakatani K, Onishi T, et al. Early outcomes in Japanese dialysis patients treated with transcatheter aortic valve implantation. Circ J. 2015:79:2713-9.

17. Gaede L, Kim WK, Liebetrau C, Dörr O, Sperzel J, Blumenstein J, et al. Pacemaker implantation after TAVl: predictors of AV block persistence. Clin Res Cardiol. 2018;107:60-9

18. Lok CE. Fistula first initiative: advantages and pitfalls. Clin J Am Soc Nephrol. 2007;2:1043-53.

19. Alkhouli M, Alasfar S, Samuels LA. Valvular heart disease and dialysis access: a case of cardiac decompensation after fistula creation. J Vasc Access. 2013;14:96.

20. Ennezat PV, Maréchaux S, Pibarot P. From excessive high-flow, high-gradient to paradoxical low-flow, low-gradient aortic valve stenosis: hemodialysis arteriovenous fistula model. Cardiology. 2010;116:70-2.

21. Kajbaf S, Veinot JP, Ha A, Zimmerman D. Comparison of surgically removed cardiac valves of patients with ESRD with those of the general population. Am J Kidney Dis. 2005:46:86-93.

22. Hamilton P, Coverdale A, Edwards C, Ormiston J, Stewart J, Webster M, et al. Transcatheter aortic valve implantation in end-stage renal disease. Clin Kidney J. 2012;5:247-9.

23. Schymik G, Bramlage P, Herzberger V, Bergmann J, Conzelmann LO, Würth A, et al. Impact of dialysis on the prognosis of patients undergoing transcatheter aortic valve implantation. Am J Cardiol. 2019:123:315-22.

24. Smith CR, Leon MB, Mack MJ, Miller DC, Moses JW, Svensson LG, et al. PARTNER trial investigators. Transcatheter versus surgical aortic-valve replacement in high-risk patients. N Engl J Med. 2011:364:2187-98.

25. Szerlip M, Zajarias A, Vemalapalli S, Brennan M, Dai D, Maniar H, et al. Transcatheter aortic valve replacement in patients with end-stage renal disease. J Am Coll Cardiol. 2019;73:2806-15.

26. Bhatia N, Agrawal S, Yang S, Yadav K, Agarwal M, Garg L, et al. In-hospital outcomes of transcatheter aortic valve implantation in patients with endstage renal disease on dialysis from a large national database. Am J Cardiol. 2017:120:1355-8.

27. Szerlip M, Kim RJ, Adeniyi T, Thourani V, Babaliaros V, Bavaria J, et al. The outcomes of transcatheter aortic valve replacement in a cohort of patients with end-stage renal disease. Catheter Cardiovasc Interv. 2016;87:1314-21.

28. Dumonteil N, van der Boon RM, Tchetche D, Chieffo A, Van Mieghem NM, Marcheix B, et al. Impact of preoperative chronic kidney disease on shortand long-term outcomes after transcatheter aortic valve implantation: a Pooled-RotterdAm-Milano-Toulouse In Collaboration Plus (PRAGMATIC-Plus) initiative substudy. Am Heart J. 2013;165:752-60.

29. Rau S, Wessely M, Lange P, Kupatt C, Steinbeck G, Fischereder M, et al. Transcatheter aortic valve implantation in dialysis patients. Nephron Clin Pract. 2012;120:c86-90.

\section{Publisher's Note}

Springer Nature remains neutral with regard to jurisdictional claims in published maps and institutional affiliations. 